\title{
EXTERNAL JUGULAR VEIN FOR RAPID TRANSFUSION DURING SURGERY*
}

\author{
H. B. KeEnleyside, M.D. †
}

ONE OF THE MOST IMPORTANT PRoBlems the anaesthetist has to face is the contemporaneous replacement of blood loss in major surgery and provision of a site for massive transfusion in the event of a vascular catastrophe. In many patients the veins of the upper extremity provide an inadequate channel for such purposes, or the arm is inaccessible during operation. In other cases the saphenous vein of the lower extremity cannot be used because of the operative posture of the patient or because the continuity of the inferior vena cava may be interfered with during surgery. Further, during shock or hypothermia the peripheral veins become constricted and transfusion rate slows, at a time when rapid flows are most needed. Peripheral venous constriction in shock may be further increased if vasopressors are administered. ${ }^{1-3}$ In addition, the veins of the extremities usually become constricted during transfusion of cold bank blood. Finally, the saphenous or cephalic veins may be found thrombosed by previous infusions when the patient is seen in the operating room. Rarely, severe damage to an extremity may follow transfusion of cold blood in patients with poor peripheral circulation. ${ }^{4}$

The external jugular is a large, thin-walled distensible vessel, so that a huge blood flow through it is possible. Distensibility of the vessel is apparent when a small child cries vigorously, when a man lifts something heavy, or in an individual with congestive heart failure. In a vein with a given wall tension, if the intravascular pressure is suddenly increased, the tension at first is raised, but it then disappears as the smooth muscles in the wall of the vein relax. This effect is called stress-relaxation. It refers to the fact that when the tone of a blood vessel is poor, the innate capacity of the smooth muscles to respond to stretch by contracting is absent, and only passive distension occurs.

For blood flow in a large thin-walled vein, Poiseuille's law applies:

$$
\text { B.F. } \propto \frac{\text { B.P. } \times D^{4}}{V \times L},
$$

where B.P. = blood pressure, $D=$ diameter of vessel, $V=$ viscosity of blood, $L=$ length of vessel (laminar How). In comparison with the saphenous or cephalic veins, the external jugular is more distensible and has a wider lumen and shorter length. These factors reduce resistance to blood flow for any given pressure gradient and blood viscosity.

High-pressure transfusion is undesirable. Haemolysis occurs when a jet of blood enters the vein. Very high pressures may be attained ( up to several hundred

- Presented at the Annual Meeting, Canadian Anaesthetists' Society, May 14-17, 1962.

iDepartment of Anaesthesia, University of Western Ontario, and Victoria Hospital, London, Ontario. 
millimetres of mercury) and cause sudden overloading of the right side of the heart.

\section{Clinical Use of Rapi Transfusion via the Jugular Vein}

Transfusion rates were recorded in 31 normotensive good-risk subjects (No. 16 needle). With increased venous distensibility during anaesthesia, transfusion rates via the external jugular and cephalic veins were similar, but via the saphenous they were slower. Immediately after anaesthesia, reduced distensibility of peripheral veins occurs while jugular distensibility remains unchanged (Table I). Reduced distensibility of saphenous and cephalic veins also occurs

TABLE 1

Transfusion Rates in Normotensive Good-Risk Surjlicts

\begin{tabular}{lccc}
\hline & & Average time per unit of blood (mnutes) \\
\cline { 3 - 4 } \multicolumn{1}{c}{ Vein } & $\begin{array}{c}\text { Number } \\
\text { of cases }\end{array}$ & $\begin{array}{l}\text { During } \\
\text { anaesthesia }\end{array}$ & $\begin{array}{c}\text { After } \\
\text { andesthesia }\end{array}$ \\
\hline Saphenous & 7 & 130 & 185 \\
Cephalic & 15 & 95 & 140 \\
Ext. jugular & 9 & 85 & 90 \\
\hline
\end{tabular}

during shock, with administration of vasoconstrictors, or after repeated transfusion of cold bank blood.

Jugular vein transfusion has been employed in approximately 70 major procedures during an 18-month period. With the transfusion bottle 5-6 feet above heart level, one unit of blood can be transfused within 5 minutes (No. 14 needle). Rapid transfusion is maintained through the external jugular during shock, positive pressure being seldom necessary. The sooner the blood reaches the heart the better; and the jugular vein offers a much shorter route than veins of the extremities do. The right vein is almost directly in line with the superior vena cava and right atrium.

The method has proved invaluable during emergency cardiovascular operations in elderly patients. In such cases, the jugular route has often becn substituted for one or more transfusions slowly dripping into poor peripheral veins. A widebore needle is easily placed in the external jugular, which is prominent in the elderly. Massive transfusion through the cephalic vein near the shoulder has been described, but this requires surgical exposure. ${ }^{b}$

Transfusion through the external jugular has been most useful in the following situations:

1. Cardiovascular surgery: (i) resection and graft-ruptured aortic aneuryşm; (ii) mitral valvotomy, division of patent ductus, resection of anrtic coarctation; (iii) thoracic aortic and intracardiac surgery.

2. General and thoracic surgery: (i) abdominal-perineal resections, radical pelvic operations; (ii) radical pneumonectomy, oesophagectomy, pleural decortication. 
3. Emergencies: (i) ruptured liver or spleen; (ii) massive burns or multiple injuries (where the extremities are widely involved).

\section{Case Reports}

\section{Case 1}

Patient H., a 70-year-old man, was admitted to hospital in profound shock and severe pain. Blood pressure was $60 \mathrm{~mm}$. Hg systolic, and a pulsating expansile mass was felt in the lower abdomen. A diagnosis of ruptured aortic aneurysm was made; transfusion was allowed to run slowly at first, as some hypotension was considered desirable until surgery could be started. After induction of anaesthesia a No. 14 needle was placed in the right external jugular. As the abdomen was being opened, a fast transfusion was started in order to minimize the fall in blood pressure on' release of the abdominal compression. Large amounts of clotted and unclotted blood were evacuated from the peritoneal cavity and a leaking aneurysm below the level of the renal arteries was found. The aorta was clamped just below the renals. During resection of the aneurysm a small tear in the vena cava occurred; very fast transfusion was restarted, and the vena cava was occluded and repaired. Blood pressure fell to $70 \mathrm{~mm}$. $\mathrm{Hg}$ (systolic) after caval occlusion, but returned quickly to $100 \mathrm{~mm}$. $\mathrm{Hg}$ with transfusion. On removal of the caval clamps 20 minutes later, the blood pressure recovered further. Resection and graft of the abdominal aorta was then completed; hypotension occurring after removal of the aortic clamps was treated with metaraminol and transfusion. Recovery was satisfactory.

\section{Case 2}

Patient R., an 89-year-old man, was admitted with a-large pulsating mass in the right upper thigh. Blood pressure was $86 / 60$. A diagnosis of ruptured femoral artery aneurysm was made, and rapid transfusion started in the operating room. Blood pressure improved temporarily but while the right lower extremity was being prepared for surgery, the mass increased rapidly in size and blood pressure dropped again. Transfusion was continued rapidly; as the skin incision was made a huge blood loss occurred before the femoral artery could be clamped, and blood pressure was unrecordable. With further transfusion and metaraminol intravenously, the blood pressure recovered. After resection and graft of the femoral aneurysm and removal of the femoral artery clamp, hypotension recurred. Treatment again was with fast transfusion and metaraminol intravenously. The postoperative course was satisfactory for over 2 weeks, when the patient suddenly expired.

\section{Case 3}

Patient H., a 74-year-old man, underwent ilioprofunda by-pass graft and lumbar sympathectomy for right iliac and femoral aneurysms. Several hours postoperatively he developed shock, and did not respond to transfusion; he was thought to be bleeding into retroperitoneal tissues. Blood pressure was $80 \mathrm{~mm}$. Hg systolic (normally 180/120). When the abdomen was re-explored, large quantities of old blood were evacuated and the blood pressure became unrecordable. Immediate transfusion via the jugular route was necessary to replace blood loss. While bleeding from lumbar veins was being controlled, a small tear in the vena cava occurred. This was repaired and the remainder of the postoperative course was satisfactory.

The following history illustrates the utility of transfusion via the jugular route as a resuscitative procedure before emergency operation.

\section{Case 4}

This 80-year-old man with severe coronary artery disease and frequent episodes of angina pectoris was admitted to hospital for prostatectomy. Occasionally he had 
suffered angina decubitus and on admission had marked peripheral oedema and other signs of cardiac failure. Blood pressure was $150 / 80$ and the E.C.G. showed an old myocardial infarction. Two weeks following transurethral resection he developed secondary haemorrhage from the prostatic bed, and at this time experienced a prolonged bout of retrosternal pain. With repeated transfusions the blood pressure was maintained at $115 / 60$, but as bleeding persisted he was brought to the operating room. In the operating room, blood pressure was $90 / 50$ and previous signs of cardiac failure absent. As suitable veins in the upper extremity were absent, rapid transfusion through the external jugular was started. When $750 \mathrm{cc}$. of blood had been administered the patient was anaesthetized and one large prostatic artery promptly fulgurated. Immediately after operation he required a further $250 \mathrm{cc}$. of blood, which, however, was followed by basal pulmonary congestion. He was digitalized and given a diuretic. (The jugular infusion was replaced by one in the upper extremity 12 hours later.) The remainder of the postoperative course was smooth although a subsequent E.C.G. showed a probable recent myocardial infarction.

\section{Technique and Applications}

The external jugular is thinner-walled and more mobile than the saphenous or cephalic veins, so that venipuncture must be meticulous. For success the anaesthetist should be able to make a venipuncture without the use of a syringe or tourniquet. This can be easily learnt after a little practice on the veins of the upper extremity. By hanging the extremity dependent over the edge of the.

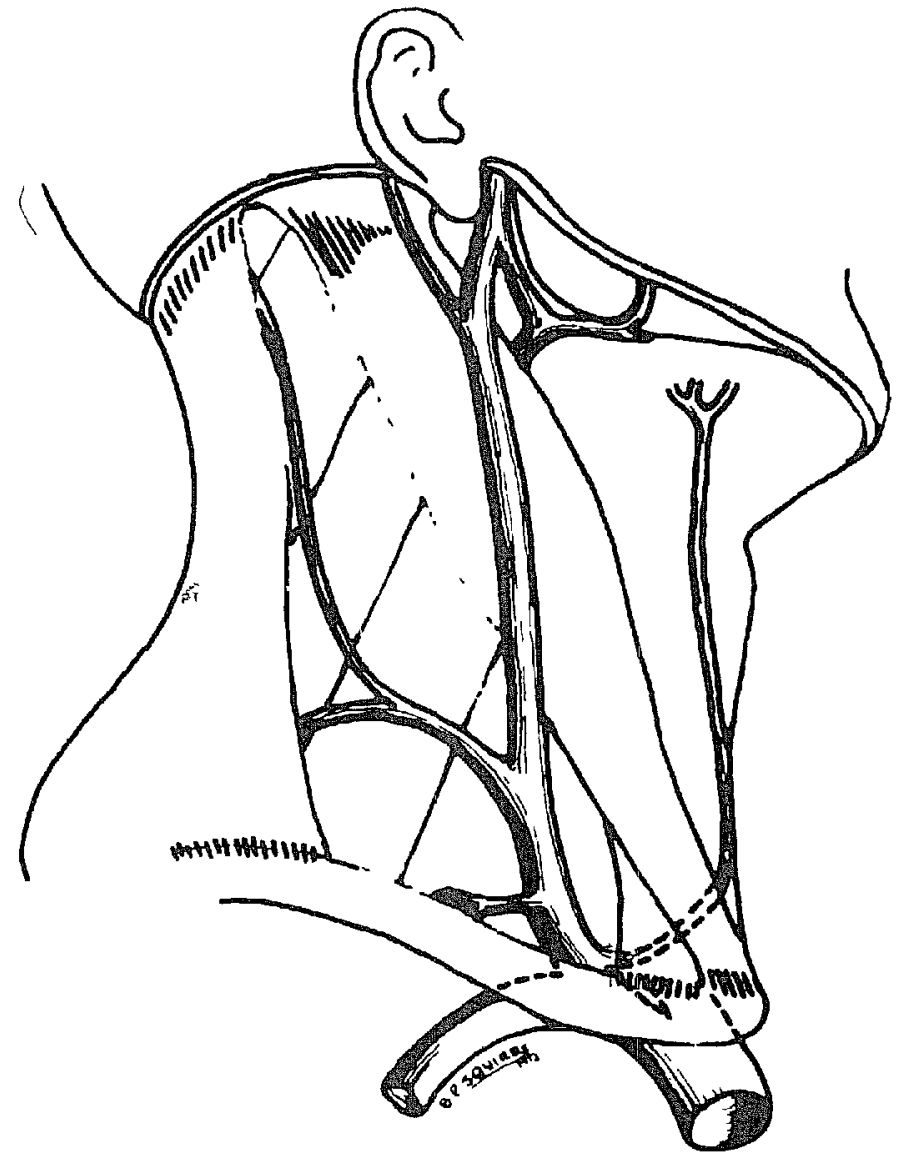

Figure 1 
operating table, the veins fill by gravity, and then puncture is quite simple in most patients. The external jugular can similarly be distended by placmg the patient in the Trendelenburg position, or by having an assistant apply pressure over the vein at the upper border of the clavicle For the puncture a No. 14 needle attached to the intravenous tubing is used, with the patient's head turned slightly to the opposite side. Use of a syringe not only makes venupuncture more difficult, but also adds some risk of air embolssm when disconnected from the needle in the vein. The Rochester plastic needle (No, 15-18) ${ }^{*}$ is useful in children to prevent interstitial displacement.

Venipuncture may be faclitated by pulling the skin taut over the lower border of the mandible, using a gauze square for traction. Puncture is best made on the lateral side of the vein with the needle tp not extending mugh below the lower border of the sternomastoid (Figure 1). The infusion tubing usually lies flat in the groove between the lobe of the ear and angle of the mandible, and passes upwards just in front of the ear (Figures 2 and 3 ). Puncture on the medial

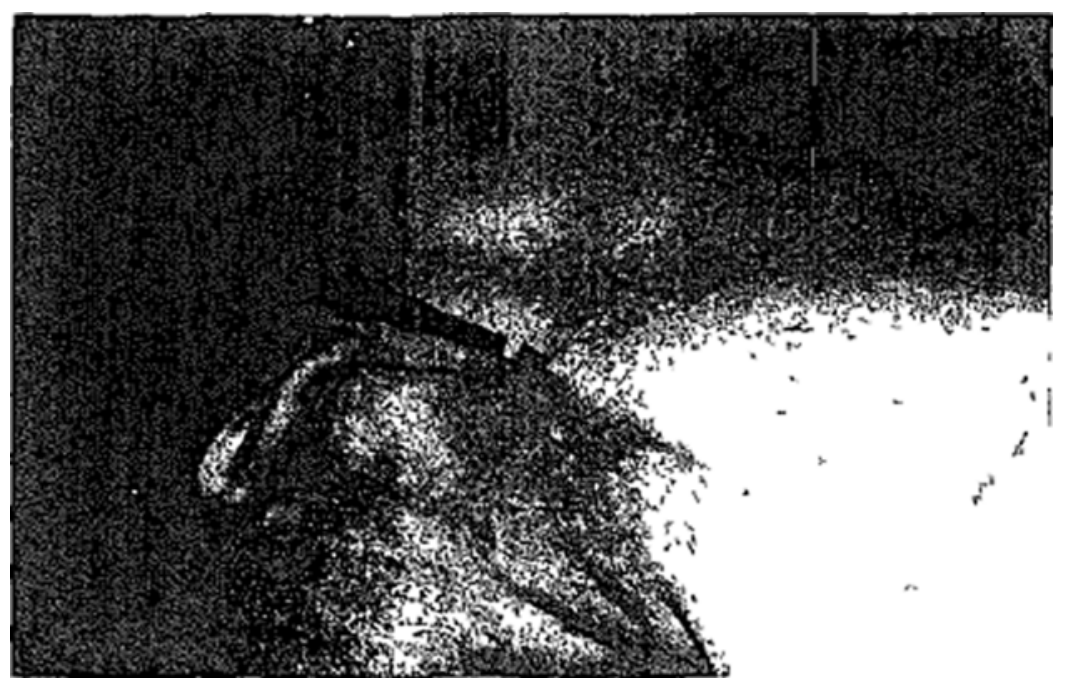

Figure 2

side of the vein is also satisfactory but the infusion tubing tends to cross the angle of the mandible instead of Jymg flat in front of the ear The jugular puncture should be performed mmediately after induction and posturing of the patient but before the drapes are applied, as it may be more difficult to do once surgery has commenced and the patient is hidden under the drapes

In a 2-year-old chld undergoing extensive skin-grafting for a severe avulsion injury of the lower extremities, the jugular transfusion (No. 18 needle) did not run interstitial during movement of the child from the supme to the prone position midway through the operation.

Jugular vein transfusion is most applicable for rapid intı-operative blood replacement or for resuscitation preceding emergency operation. For postoperdtive transfusion and fluid therapy a perpheral venipuncture is usually substituted However, if peripheral veins are unsuitable a jugular infusion may be left in

-Avarlable from V Mueller \& Co, Chıcago 12, Illinois 


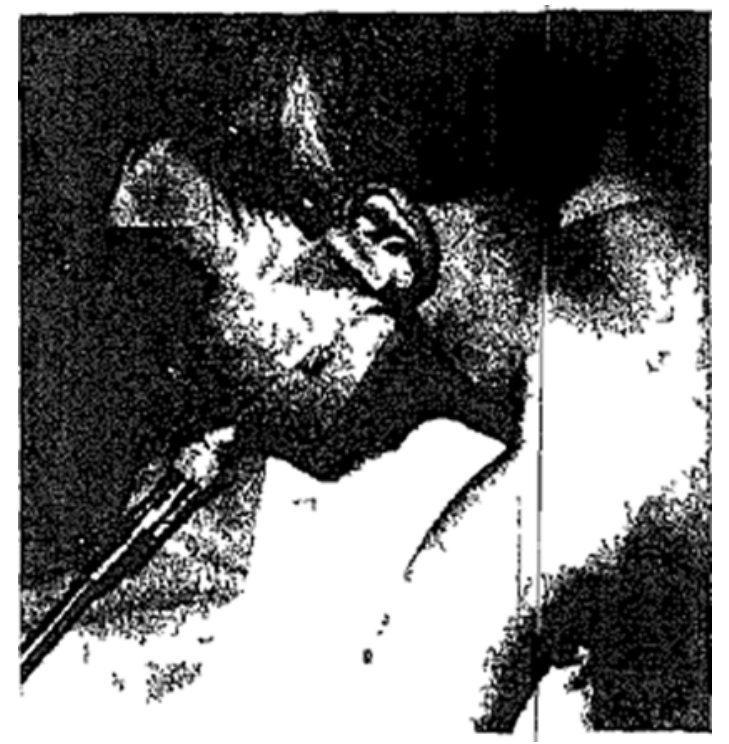

Figuae 3

place postoperatively with advantage In the small child with an extensive avulsion myury, the jugular infusion was allowed to remain in place for several hours after operation

Postoperative flud therapy va the external jugular does not produce venous thrombosis because of the wide calıbre of the vem and absence of venous spasm W'th peripheral infusions on the other hand venous thrombosis or merely pam and induration occur just provimal to the needle to after a vanable period of trme This is due to the fact that the vem is usually in spasm around the needle, and the vasa venorum are then perfused by a glucose solution mstead of blood, with ensuung endothelial damage and thrombosis ${ }^{\top}$ Agannst the postoperatuve use of jugular infusions however is the fact that if the infusion tubing is removed from the needle arr embolsm maly occur

When noradrenalune is given to shocked pitients infusion into a large vem such as the external jugular is much safer than mto collapsed peripheral veins The risk of tissue necrosis occurring over a peripheral infusion site is greatly mcreased owing to high councentrations of noradrenaline withon the vein lumen ${ }^{18}$ A noradrenaline infusion is also more likely to extravasate from a constructed pexpheral site

\section{Coviplicatiovs a $\backslash$ D Phecautio $\backslash$ s}

No selious complic itions arising from this method have been encountered Interstital displacement of the needle during transfusion has not occurred, and is considered unlukely owng to the large calibie of the vein and absence of spasm The vern is also so mobile that it tends to shift with movement of the needle instead of being pierced However, if there is concern on this point, cut down on the external jugular using wide bore polyethylene tubing may be substututed

During active blood loss the rate of transfusion camnot usually be too fast Rapid transfusion can be dangerous however, in patsents with myocardial 
damage, if the heart is unable to handle the venous return (Case 4, p. 514). In such patients hypotension may be due more to cardiac failure than to low blood volume. ${ }^{8}$ Severe cardiac disturbances may also result from cold citrated blood rapidly reaching the right heart, especially in poor-risk patients. ${ }^{9,10}$

The possibility of air embolism occurring with a big needle in the jugular vein should be appreciated. The risk is present if a syringe or infusion tubing is detached from the needle, especially if the patient's head is raised. Pressure transfusion should also be avoided if possible, as it can result in fatal air embolism, particularly in patients with a patent foramen ovale. ${ }^{11,12}$

\section{Summary and Conclusions}

The most constant superficial veins for transfusion are the saphenous, cephalic, and external jugular. Frequently the veins of the extremities are unsuitable for massive intra-operative transfusion. In addition, peripheral transfusions are often accompanied by venous spasm.

The external jugular vein offers an admirable site for venipuncture and rapid transfusion. The vessel is large, thin-walled, and distensible.

The jugular route has proved invaluable during emergency cardiovascular operations, but is indicated whenever massive transfusion is contemplated, or peripheral sites are not readily available. The jugular vein is also more accessible to the anaesthetist during the operative procedure than the saphenous or cephalic veins.

The external jugular may also be used for resuscitation preceding emergency operation, and for transfusion and fluid therapy postốperatively. Its use postoperatively is limited by the risk of air embolism and by the fact that many patients are emotionally disturbed by an infusion in this region.

Possible complications are interstitial transfusion, cardiac failure from toorapid transfusion, and venous air embolism.

\section{RÉSUMÉ}

Les veines superficielles le plus souvent employées pour les transfusions sont les veines saphènes, jugulaires externes et céphaliques. Fréquemment, les veines des extrémités sont peu propices aux transfusions massives per-opératoires; de plus, elles sont souvent le siège de spasmes veineux.

La veine jugulaire externe, à paroi mince et extensible, à large lumière, est le site idéal pour une vénisection et une transfusion rapide. Cette voie est excellente au cours des interventions cardiovasculaires urgentes; elle est aussi indiquée pour les transfusions massives où l'on ne peut trouver une voie périphérique. Elle est également plus accessible pour l'anesthésiste, au cours des interventions chirurgicales, que la saphène ou la céphalique.

La veine jugulaire externe peut être utilisée en ressuscitation avant une opération d'urgence, ou post-opératoirement pour l'administration 'de transfusions et de solutés; mais, dans ce dernier cas, l'emploi en est limité à cause du danger d'embolie gazeuse et des troubles émotionnels que peuvent produire des perfusions à cet endroit. 
Les complications possibles sont: la transfusion interstitielle, l'embolie gazeuse et la défaillance cardiaque lors de transfusions trop rapides.

\section{ACKNOWLEDGMENTS}

My thanks are due to Drs. W. E. Spoerel and J. C. Coles for their interest and advice during the preparation of this report.

\section{REFERENCES}

1. Watson, W. E., \& Seelye, E. Vascular Distensibility of the Hand during Reduction of the Effective Blood Volume in Man. Brit. J. Anaesth. 34: 74 (1962).

2. Glover, W. E.; Greenfield, A. D. M.; Kidd, B. S. L.; \& Whelan, R. F. The Reactions of the Capacity Blood Vessels of the Human Hand and Forearm to Vaso-active Substances Infused Intra-arterially. J. Physiol. 140: 113 (1958).

3. Burch, G. E., \& Muntadha, M. A Study of the Venomotor Tone in a Short Intact Venous Segment of the Forearm of Man. Am. Heart J. 51: 807 (1956).

4. Vaughan, A. B. Severe Damage to Limb after Blood Transfusion. Brit. Med. J. 11: 1097 (1952).

5. Alexander, R. S. Functional Properties of Blood Vessels. Third Conference on Shock and Circulatory Homeostasis, pp. 197-206. New York: Josiah Macy, Jr. Foundation (1953).

6. Dolton, E. G. Massive Blood-Transfusion Through the Cephalic Vein. Lancet i: 1052 (1955).

7. Malone, R. G. Personal communication.

8. Keown, K. K., \& Rax, C. T. Diagnosis and Treatment of Heart Failure in the Operating Room, Anesth. \& Analg. 40:87 (1961).

9. Boyan, C. P., \& Howland, W. S. Blood Temperature: A Critical Factor in Massivè Transfusion. Anesthesiology, 22: 559 (1961).

10. Bunker, J. P.; Bendixen, H. H.; \& MurPrix, A. J. Hemodynamic Effects of Intravenously Administered Sodium Citrate. New Eng. J. Med. 266: 372 (1962).

11. Ruesch, M.; Mryatake, S.; \& Balimger, C. M. Continuing Hazard of Air Embolism during Pressure Transfusions. J.A.M.A. 172: 1476 (1960).

12. Bewes, P. C. Danger of Air Embolism in High-Pressure Blood-Transfusions. Lancet i: 429 (1961).

13. Humphreys, J.; Johnston, J. H.; \& Richardson, J. C. Skin Necrosis Following Intravenous Noradrenaline. Brit. Med. J. 11: 1250 (1955). 